\section{STUDY OF PREVALENCE OF NEPHROPATHY IN NEWLY DIAGNOSED TYPE 2 DIABETES MELLITUS PATIENTS}

KEY WORDS: Type2 diabetes mellitus, Microalbuminuria, Nephropathy

\section{Dr. Abhijeet}

Kumar

\section{Dr. Pankaj Hans*}

Dr Ram Raj Ravi
Junior Resident, Department of General Medicine, Patna Medical College \& Hospital, Patna- 800004

Associate Professor., Department of General Medicine, Patna Medical College \& Hospital, Patna- $800004 *$ Corresponding Author \\ INTRODUCTION: Diabetes Mellitus is one of the commonest diseases of the world. The dangerous fact about diabetes is that it is "Silent Killer". By the time patient is diagnosed to have diabetes, he/she is already affected with complications like diabetic nephropathy, retinopathy and neuropathy. It is specially worse in India, where various factors delay the diagnosis of diabetes compared to developed nations. Diabetic nephropathy and microalbuminuria are also strong predictors of cardiovascular and overall mortality in patients of diabetes, and hence are vital indicators in the patients. AIM: To find out prevalence of nephropathy in newly diagnosed Type 2 diabetes mellitus patients and other complications. \\ METHODS: .In this cross-sectional study first 100 pts from PMCH Medicine OPD and IPD of age>20yrs of type2 diabetes mellitus during study period were taken and evaluated for HbAlc, urea, creatinine, Microalbuminuria, LVH, \& blood sugar levels. \\ RESULT: .It was found that $34 \%$ of patients of type 2 diabetes mellitus have developed nephropathy at the time of detection. Among these 34 patients 18 have developed LVH and 13 out of 66 diabetic patients developed LVH. Result is significant with $\mathrm{p}<0.001 .92 \%$ of newly diagnosed diabetic patients have $\mathrm{HbAl} \mathrm{c}>7.5 \%$ ( $\mathrm{p}=0.01$ significant) \\ CONCLUSION:. diabetic nephropathy is much larger than imagined in freshly diagnosed/new onset cases of DM type 2 , especially compared to more developed nations. Microalbuminuria in patients with diabetes is a potential risk factor not only for kidney function impairment but also a marker for high risk of cardiovascular complications.
}

\section{INTRODUCTION:}

Diabetes Mellitus is a disease where our body is not able to maintain glucose homeostasis and this leads to High Glucose levels in the patient's body. It is one of the commonest non communicable disease known to mankind especially in the industrialized world. Diabetes Mellitus can be confirmed by either plasma glucose in random sample or $2 \mathrm{hrs}$ after a $75 \mathrm{~g}$ glucose load $>200 \mathrm{mg}$ or fasting plasma glucose $>126 \mathrm{mg} / \mathrm{dl}$ or $\mathrm{HbAlc}>6.5 \%$.

Diabetic Nephropathy is the leading cause of Chronic kidney Disease in patients starting renal replacement therapy and is associated with increased cardiovascular mortality.Diabetic Nephropathy have been classically defined by the presence of proteinuria $>0.5 \mathrm{~g} / 24 \mathrm{hr}$ (Now this stage is termed as overt or clinical nephropathy,proteinuria or Macroalbuminuria. Diabetic Nephropathy can be classified as Incipient and overt nephropathy. We can also use term Microalbuminuria and Macroalbuminuria for the same. Although microalbuminuria has been considered a risk factor for macroalbuminuria, not all patients progress to this stage and some may regress to normoalbuminuria.

Studies have shown that Diabetic nephropathy itself is a risk factor for other complications of diabetes mellitus e.g. Cardiovascular diseases, Retinopathy, Neuropathy etc.

Hence it is important to know the prevalence of Diabetic nephropathy in newly diagnosed patients of diabetes mellitus patients so that we could manage it timely and prevent other complications.

\section{AIM}

- Prevalence of Nephropathy in newly diagnosed Type 2 Diabetes Mellitus patients.

- To assess the Prevalence of microalbuminuria and macroalbuminuria in newly diagnosed type 2 diabetes mellitus patients.
- Relation of nephropathy with Left Ventricular Hypertrophy METHODS

Study Population: 100 patients of newly diagnosed type 2 Diabetes Mellitus patients aged $\geq 20$ years from the Department of Medicine OPD and IPD, Patna Medical College, Patna, Bihar were selected for the study. All the patients underwent detailed history taking, clinical examination and blood examination of Glucose, HbAlc Microalbumin, Urea and Creatinine.

Study Period: Total study duration was 14 months, from November 2018-December 2019

Sample Size: Total 100 patients of newly diagnosed Diabetes Mellitus patients taken then they were searched for Nephropathy Prevalence. Then they were divided in 2 groups One with nephropathy and other without nephropathy.

Study technique: Cross sectional observational study. Study design:Prevalence study

\section{Statistical Analysis:}

Categorical variables were presented as numbers and percentages. All descriptive data was expressed as Mean \pm standard deviation and percentages. Chi-square test was used to assess the association among different categorical variables. Correlation was performed to find out the relation between different continuous variables. For all statistical analyses $p<0.05$ was considered statistically significant. The data was analyzed using computer software Microsoft Excel and SPSS version 19.0 forWindows.

\section{Sample Design:}

\section{Case definition:}

- Diabetes was diagnosed as per guidelines stated by American Diabetic Association Diagnostic criteria, 2018.

- Fasting $\mathbf{C}$ peptides were done cases where the doubts in differentiating type 1 and type 2 diabetes.

\begin{tabular}{|c|c|c|}
\hline Submitted : $11^{\text {th }}$ November, 2019 & ${\text { Accepted }: 19^{\text {th }} \text { January, 2020 }}^{\text {Publication : 15 }}$ February, 2020 $^{\text {th }}$ \\
\hline www.worldwidejournals.com $\mid$ & \\
\hline
\end{tabular}


- Newly diagnosed type 2 Diabetes Mellitus: A case of type 2 Diabetes mellitus diagnosed within last 6 months of presentation was arbitrary considered as newly diagnosed type 2 diabetes mellitus.

\section{Case Selection:}

\section{A. Inclusion Criteria:-}

- Newly diagnosed Type 2 Diabetes Mellitus (Newly diagnosed arbitrary fixed at or $<6$ months)

- Aged $\geq 20$ years

\section{B. Exclusion Criteria:-}

- Patients aged less than 20 years

- Patients of type 2 Diabetes mellitus already diagnosed with or without treatment $>6$ months.

- Diabetes mellitus other than type 2 Diabetes Mellitus.

- Primary and secondary renal disease.

- Patients having confounding factors like fever, pregnancy, women in menstrual period, urinary tract infections and congestive cardiac failure.

\section{Case Definition}

\section{Methodology}

Detail clinical history and significant findings were noted after explanation of procedure and taking informed consent of patient. 100 patients of newly diagnosed type 2 Diabetes Mellitus patients aged $\geq 20$ years from the Department of Medicine OPD and IPD, Patna Medical College, Patna, Bihar were selected for the study. All the patients underwent detailed history taking, clinical examination and blood examination of Glucose, HbAlc , Microalbumin, Urea and Creatinine.

\section{RESULTS}

Table 1: Prevalence of Nephropathy

\begin{tabular}{|c|c|c|}
\hline Nephropathy & Frequency & Percentage \\
\hline Present & 34 & 34 \\
\hline Absent & 66 & 66 \\
\hline Total & 100 & 100 \\
\hline
\end{tabular}

\section{Figure 1: Prevalence of Nephropathy}

\section{Prevalence of Nephropathy}

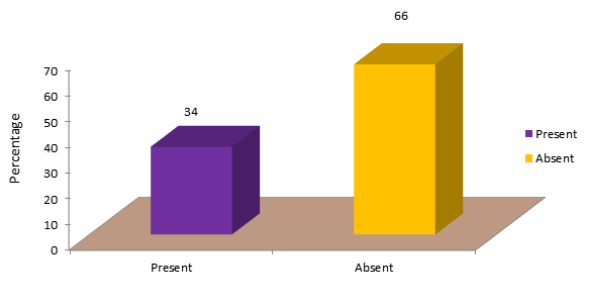

Table 1 shows that the prevalence of nephropathy of our study was $34 \%$. $66 \%$ patients were presented without nephropathy.

Table 2: Association between different parameters with Nephropathy status

\begin{tabular}{|c|c|c|c|c|}
\hline \multirow{2}{*}{ Variables } & \multicolumn{2}{|c|}{ Nephropathy Status } & Chi square & $\begin{array}{c}\mathrm{p} \\
\text { value }\end{array}$ \\
\cline { 2 - 3 } value
\end{tabular}

Table 2 shows association between different parameters like sex, $\mathrm{HbAl}$ c level, USG findings, ECG findings and prevalence of microalbuminuria between study participants with or without nephropathy. On apply of chi-square test, association was found to be statistically significant for $\mathrm{HbAlC}(p=0.01)$, ECG finding $(p=<0.001)$ and prevalence of microalbuminuria $(\mathrm{p}<0.001)$.

\section{CONCLUSION}

Results of the present study conclude:

- The incidence of nephropathy in newly diagnosed type 2 diabetics is as high as $34 \%$ which indicates diabetic nephropathy is much larger than imagined in freshly diagnosed/new onset cases of DM type 2, especially compared to more developed nations. The incidence of nephropathy has significant correlation with poor glycemic control (high HbAlc level), sedentary life style (high BMI), age, male sex.

- There is significant evidence to support the conclusion that microalbuminuria in patients with diabetes is a potential risk factor not only for kidney function impairment but also a marker for high risk of cardiovascular complications

\section{REFERENCES}

1. Bayauli MP, Lepira FB, Kayembe PK, M'Buyamba-Kabangu JR. Left ventricular hypertrophy and geometry in type 2 diabetes patients with chronic kidney disease. An echocardiographic study. Cardiovascular J Africa. 2012 Mar;23(2):73-7.

2. Chapter 1: Definition and classification of CKD. Kidney Int Suppl (2011) 2013; 3:19

3. Copeland KC, Zeitler P, Geffner M, et al. Characteristics of adolescents and youth with recent-onset type 2 diabetes: the TODAY cohort at baseline.J Clin Endocrinol Metab 201 1;96:159.

4. Pinhas-Hamiel O, Zeitler P. Acute and chronic complications of type 2 diabetes mellitus in children and adolescents. Lancet 2007;369:1823.

5. Rodriguez BL, Dabelea D, Liese AD, et al. Prevalence and correlates of elevated blood pressure in youth with diabetes mellitus: the SEARCH for diabetes in youth study.J Pediatr 2010; 157:245

6. TODAY Study Group. Rapid rise in hypertension and nephropathy in youth with type 2 diabetes: the TODAY clinical trial. Diabetes Care 2013; 36: 1735-1741

7. Ismail N, Becker B, Strzelczyk P, Ritz E. Renal disease and hypertension in noninsulin-dependent diabetes mellitus. Kidney Int 1999;55:1.

8. Bakris GL, Molitch M. Microalbuminuria as a risk predictor in diabetes: the continuing saga.Diabetes Care 2014;37:867.

9. KDOQI. KDOQI Clinical Practice Guidelines and Clinical Practice Recommendations for Diabetes and Chronic Kidney Disease. Am J Kidney Dis $2007 ; 49: \mathrm{S} 12$

10. Lambers Heerspink HJ, Gansevoort RT, Brenner BM, et al. Comparison of different measures of urinary protein excretion for prediction of renal events. JAm Soc Nephrol 2010;21:1355. 